Trichoderma harzianum استخدام كلوتين الذرة كوسط ملائم لتنمية الفطر

وانتاج انزيم البروتييز الحامضي

\title{
Using of Corn Gluten Growing of Trichoderma harzianum and production of acid protease
}

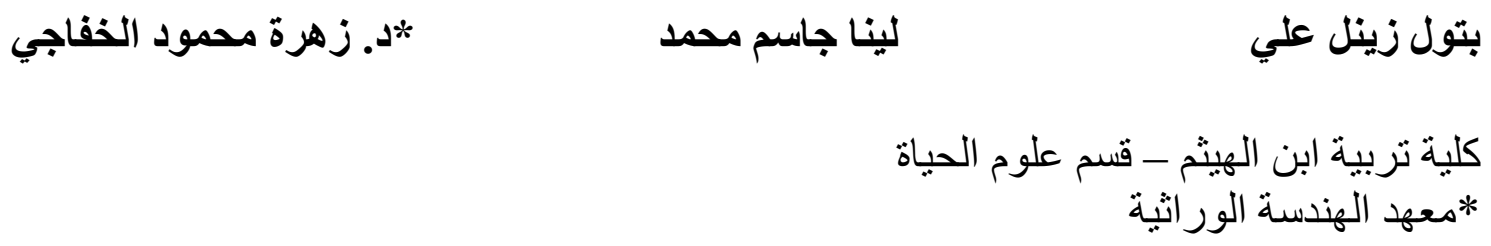

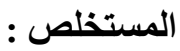

استهدفت الدراسة الحالية امكانية استخدام احد المخلفات الزراعية وهو كلوتين (Gluten) الذرة الجزء غير الذائب ولأول مرة كوسط زرعي لتنمية الفطر Trichoderma harzianum وانتاج انزيم البروتييز الحامضي بأسلوب التخمرات الصلبة ـ أظهرت النتائج قابلية الفطر العالية للنمو في وسط الكلوتين بكفاعة تضاهي كفاءة النمو على وسط المالت النموذجي لنمو الفطريات ـ كما أظهر الفطر كفاءة في انتاج البروتييز الحامضي على هذا الوسط ، اذ أظهر الانزيم فعالية تقدر بقيمة (151.41) وحدة/مل وانتاجية (908.96) وحدة/غم وفعالية نوعية

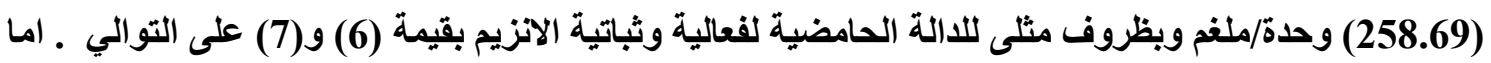
الظروف المثلى لانتاج الانزيم فكاتت بدالة حامضية (6) ودرجة حرارة (35) م و أفضل مدة حضانة لانتاج الانزيم كانت (4) أيام ـ واستخدام محلول الفوسفات الداريء كمحلول مرطب أمثل للانتاجية ، أما أفضل محلول للأستخلاص فكان داريء الخلات ، وأفضل نسبة ترطيب للكلوتين كانت بنسبة (2 : 1 1) وحجم لقاح (107) سبور/غم ، تعطي هذه النتائج مؤشراً ناجحاً لامكانية استخدام هذا الوسط لانتاج البروتييز الحامضي من قبل الفطريات .

\section{Abstract}

The study was conducted to evaluate the utilization of corn gluten which is one of the agricultural waste products "especially the insoluble solid phase" for the first time as a culturing medium for Trichoderma harzianum and production of acid protease enzyme by solid state fermentation. Results showed that the fungus had high efficiency to grow on gluten medium which was similar to its growth on malt agar medium, which is ideal for growth of fungi. In addition the fungus showed the ability produce acid protease enzyme on this medium with enzyme activity of (151.41) unit/ml and productivity of (908.96) unit/gm and specific activity (258.69) unit/mg under optimum conditions applied. pH values for enzyme activity and 
stability were (6) and (7) respectively. Whereas the optimum conditions for production of acid protease were: $\mathrm{pH}(6)$, temperature $(35)^{\circ} \mathrm{C}$ optimum incubation was (4) days, wetting solution was phosphate buffer and extracting solution acetate buffer, whereas the best wetting ratio was $(2: 1)$ and optimum inoculums size was $\left(10^{7}\right)$ spore/gm gluten. These results give successful indication of possible utilization of gluten as a culture medium and production of acid protease by the fungi.

Pepsin-like acid protease مشابهة للرنين Rennin-like acid protease مشابن وقد وجد ان البروتييزات المشابهة للبيسين يكاد ينحصر انتاجها في مجموعة الفطر Aspergillus وانواع قلبلة من جنس Penicillium اما المجمو عة

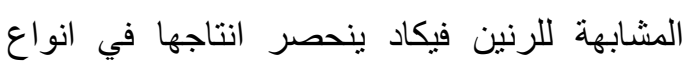

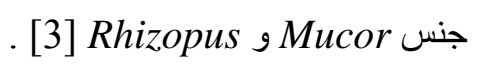
تعد مزارع التخمر ات الصلبة الاسلوب الامثل لانتاج الانزيمات من الفطريات فهي بمثابة محاكاة للطبيعة فضلا عن كونها تهيء فرصة لاستغلال مخلفات نباتية (صناعية) رخيصة كأوساط زرعية ملائمة

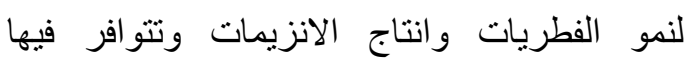
مؤشر ات الجدوى الاقتصسادية . من بين المخلفات الصناعية التي يمكن استغلالها هي هوسي

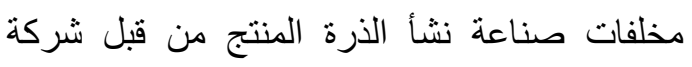
الفرات العامة (وزارة الصناعة و المعادن) التي تنتج مادة بروتين الذرة (الكلوتين) كناتج عرضي يستعمل بشكل رئبس علفا حيو انيا ولكن امكن استغلاله في تحضير بعض الاوساط الزرعية الغذائية لتنمية

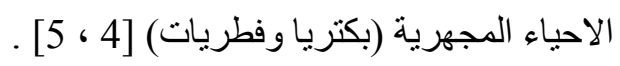
وبالنظر لاهمية انزيمات البروتييز وتوفر المواد البروتينية غير المستغلة مثل كلوتين الذرة، استهدفت

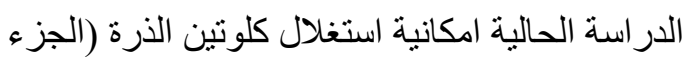

المقامسة : تحنل الانزيمات المحللة للبروتينات (البروتييزات) موقع الصدارة بين الانزيمات ذات الاهمية الصناعية. وقد توجه الاهتمام الى انزيمات البروتييز المنتجة من الاحياء المجهرية كبدائل للانزيمات الحيوانية والنباتية نظرا لسهولة تنمية هذه الاحياء

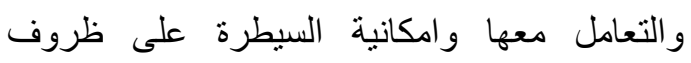
الانتاج وقصر مدته مقارنة بالمصادر الاخرى [1] . ولايكاد يخلو اي كائن مجهري من انزيمات

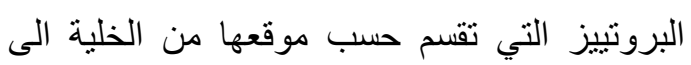

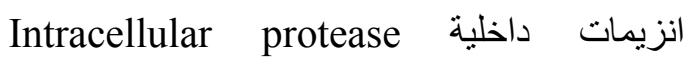
و Extracellular protease وانزيمات خارجية تفرز الاخيرة الى خارج الخلية لتحلل المواد البروتينية المعقدة الى مواد بسيطة يمكن ان تستفيد

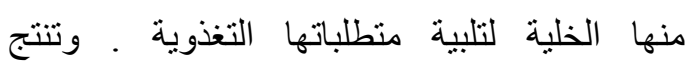
الانزيمات الخارجية بكمية كبيرة ، وهناك عشر اته الاطنان من هذه الانزيمات الخارجية نتتج سنوياً

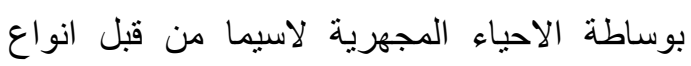

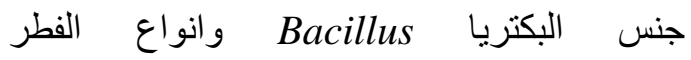
. [2] Aspergillus تصنف البروتييزات الى بروتييزات قاعدية وحامضية ومتعادلة . تعد الفطريات من اهم الاحياء المنتجة للبروتييزات الحامضية ـ تقسم البروتييزات الحامضية الى نوعين : بروتييزات مشابهة للببسين 
البروتييز الحامضي باسلوب تخمرات المواد الصلبة.

في اطباق زجاجية [6] ـ وزرع الفطر على وسط مستخلص المالت الذي يعتبر وسطا ملائما لنمو العديد من الفطريات للمقارنة ونم قياس اقطار

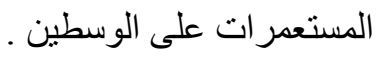
ـ اختبار كفاءة الفطر للنمو على وسط الكازيين : بعد التأكد من قابلية الفطر على انتاج انزيمات البروتييز في الفقرات السابقة نمو الفطر على وسط التخمر الصلب [9] وهو الكلوتين المرطب الذبي حضر ببعض التحوير ات [6] حيث وضع مقدار(5) غم من مستحضر الكلوتين غير الذائب في قناني زجاجية سعة (200) مل ، رطب المستحضر باضافة (10) مل من محلول الفوسفات الداريء برقم هيدروجيني (5) اي بنسبة ترطيب (1:2 )حجم : وزن ثم عقم الوسط بالمؤصدة وبرد ـ لقح الوسط بعالق ابواغ الفطر بحجم (2.5) مل (10 (3) بوغ/غم كلوتين (10) وحضن الوسط بدرجة حرارة 30م لمدة (4) ايام ، بعدها استخلصت انزيمات البروتييز [6] ـ قدرت فعالية انزيم البروتييز في بـان المستخلص وفق الطريقة المنبعة [11] وقدرت وحدات الفعالية الانزيمية ، وعرفت وحدة الفعالية بانها كمية الانزيم التي تحرر 1 مايكرومولار من التايروسين في الدقيقة عند ظروف القياس ـ كما تم تقدير البروتين حسب الطريقة المطلقة لتقدير البروتين[12] ونم تقدير الفعالبة النوعية للانزيم

حسب المعادلة :
غير الذائب) كوسط زرعي صلب لتتمية الفطر Trichoderma harzianum المواد وطرائق العمل : ـ الفطر T. harzianum و الذي كان مصدره من التربة تم الحصول عليه من مختبر الفطريات المتقدم/كلية التربية ابن الهيثم ـ ـ تم الحصول على كلوتين الذرة الخام من شركة الفرات العامة للصناعات الكيمياوية (وزارة الصناعة و المعادن) بشكل كتل صلبة مفتتة وتمت معاملته

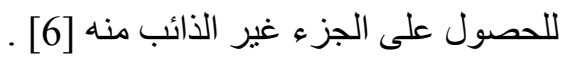
ـ اختبار استهلاك الفطر لكازيين الحليب تمت على وسط اكار الحليب الارجواني برقم هيدروجيني (6) طبقا لما معتمد في هذه الدراسات [7] ، وتم قياس قطر منطقة التحلل وقطر المستعمرة النامية ـ النتيجة الموجبة (ظهور منطقة التحلل) تدل على قدرة الفطر على انتاج انزيمات البروتييز. وكذلك اختبرت كفاءة الفطر على تحليل الكازيين اذ لذهره حضر وسط الكازبين (8) ونظم الرقم الهيدروجيني للوسط على قيم تراوحت بين (4-6) ـ بعد تنمية

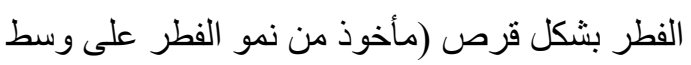
صلب) في مركز الطبق تم قياس نسبة تحليل البروتين (قطر منطقة التحلل / قطر المستعمرة) . ـ اختبار كفاءة نمو الفطر على وسط اكار الكلوتين بقيم هيدروجينية حامضية : بعد اختبار قابلية الفطر الموجبة على تحليل وسط هيل الحليب الارجواني في الفقرة السابقة زرع على وسط اكار الكلوتين الصلب المحضر من مستحضر الكلوتين غير الذائب بعد تنظيم الرقم الهيدروجيني

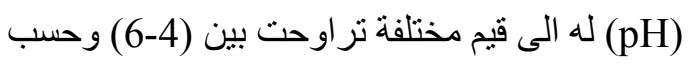

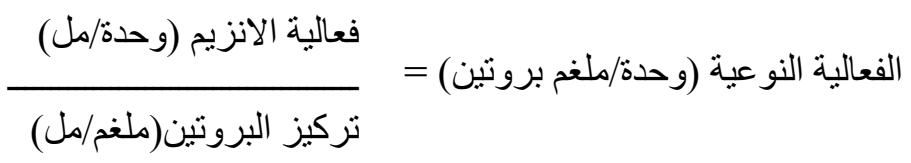


المقطر ورقم الهيدروجيني (5.5- 6) ، ماء الحنفية ورقم الهيدروجيني (5.5) واستخلص الانزيم . 4- محلول الاستخلاص الامثل : استخدمت محاليل مختلفة لاستخلاص الانزيم تضمنت : محلول

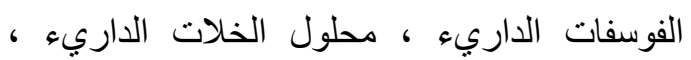
محلول السترات الداريء بتركيز (0.2) مو لار ورقم الهيدروجيني بقيمة (5) لكل من المحاليل الثلاثة كما لهاب

استخدم الماء المقطر كمحلول استخلاص ايضاً. . 5- نسبة الترطيب المنلى : رطب كلوتين الذرة بمحلول الفوسفات الداريء بنسبة نرطيب (1 : 1 ) و) 6- حجم اللقاح الامثل : استخدمت اعداد مختلفة من

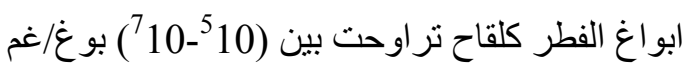

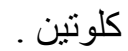
7- مدة الحضانة المثلى : رطب كلوتين الذرة بمحلول الفوسفات بنسبة (2 : 1) ولقح بابو اغ الفطر وحضنت المزارع لمدة زمنية نراوحت بين (1-8) يوم واستخلص الانزيم بصورة دورية كل (24) ساعة بمحلول الخلات الداريء .

والفطر المستعمل ينتج البروتييز الحامضي حيث أظهرت نتائج تنمية الفطر على اكار الحليب الارجواني كفاءة الفطر على تحليل الكازيين وذللك بظهور هالة التحلل حول مستعمرة الفطر النامي وتحول لون الوسط الارجواني الى الاصفر ـ بلغت نسبة التحلل بحساب قطر منطقة التحلل/قطر مستعمرة الفطر (1 : 1) ـ يعود تغير لون الوسط

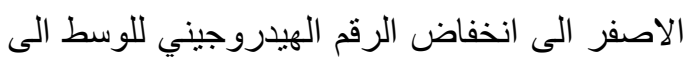

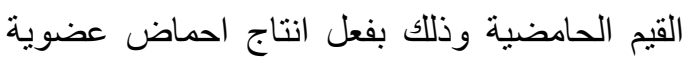
من تخمر سكريات الحليب بفعل الفطر وهكذا يكون
ـ تعيين الظروف المتلى لفعالية وثبات الانزيم الخام: استخدم محلول التفاعل 1\% كازيين بقيم هيدروجينية مختلفة (2-7) لتعيين الرقم الهيدروجيني الامثل

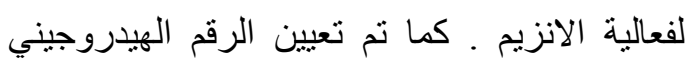
الامثل لثبات الانزيم واستخدم محلول الخلات الداريء بقيم هيدروجينية تراوحت بين (2-6) ومحلول الفوسفات الداريء برقم هيدروجيني (7)

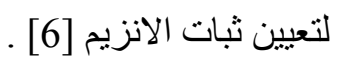
ـ تعيين الظروف المتلى لانتاج الانزيم :

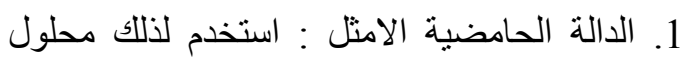
الفوسفات الداريء بتركيز (0.2) مولار كمحلول مرطب وبقيم هيدروجينية (3-7) بنسب ترطيب

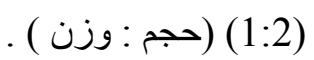
2. درجة الحرارة المنلى : حضنت مزارن مزارع الفطر المنمى على وسط الكلوتين المرطب بمحلول الفوسفات بدرجات حرارة نز اوحت بين (25-35) م لمدة (4) ايام و استخلص الانزيم . 3. محلول الترطيب الامثل : استخدمت ثلاث محاليل لترطيب الكلوتين وهي : محلول الفوسفات الداريء بتركيز (0.2) مو لار ورقم الهيدروجيني (5) ، الماء

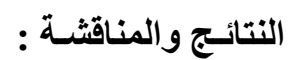
يختلف كلوتين الذرة قيد الدراسة عن باقي المخلفات الصناعية كونه مادة بروتينية فقط مقارنة بالمخلفات الزراعية والصناعية الاخرى التي تكون غنية

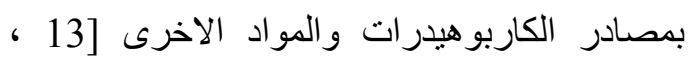
14] ، كما ان الرقم العيدروجيني لنقيعه يتراوح بين (3- 4) [4 ، 5] ، فلذلك فان كلوتين الذرة يعد حالة

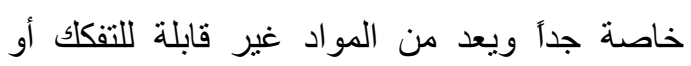
الذوبان بالمواد و المعاملات اللاحيوية حيث أخفقت محاولات اذابته بالحوامض أو القواعد القوية أو المو اد المؤكسدة أو المختزلة (دراسات غير منشورة) 
الوسط (1 : 1) وبالقيم الهيدروجينية المختلفة (4 ، 5 ، 6) مما يدل على كفاءة الفطر في انتاج البروتييز

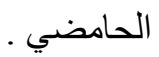

أظهرت نتائج تنمية الفظر على اكار الكلوتين ومقارنتها بوسط المالت النموذجي لنمو الفطريات

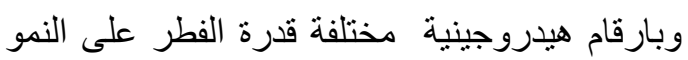
على وسط اكار الكلوتين بنفس كفاءة نموه على وسط المالت وبالقيم الهيدروجينية (4 ، 5، 6) جدول (1) .
هذا الوسط اكثر ملائمة لانتاج البروتييزات

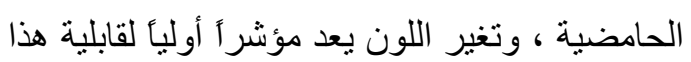
الفطر على انتاج البروتييز الحامضي عندما يكون منر افقأ بظهور منطقة تحلل حول المستعمر ات [15] وقد استخدم هذا الوسط من قبل العديد من الباحثين

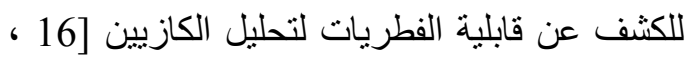
17 ، 18] ـ أما تتمية الفطر على وسط الكازبين بقيم هيدروجينية مختلفة فكانت نسبة التحلل على هذا ملى

جدول (1) نمو الفطر (أقطار المستعمرات) T. harzianum على وسط اكار الكلوتين والمالت بقيم هيدروجينية

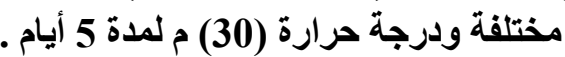

\begin{tabular}{|c|c|c|c|c|c|c|c|c|c|c|}
\hline \multicolumn{10}{|c|}{ أقطار المســتـعرات ( ســم ) } & \multirow{3}{*}{ 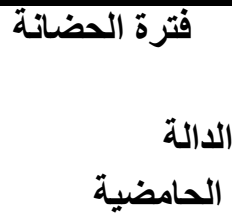 } \\
\hline \multicolumn{2}{|c|}{ اليوم الخامس } & \multicolumn{2}{|c|}{ اليوم الرابع } & \multicolumn{2}{|c|}{ اليوم الثالث } & \multicolumn{2}{|c|}{ اليوم الثاني } & \multicolumn{2}{|c|}{ اليوم الأول } & \\
\hline M & G & M & G & M & G & M & G & $\mathrm{M} * *$ & $\mathrm{G} *$ & \\
\hline 9.0 & - & 8.8 & 9.0 & 7.8 & 8.2 & 4.1 & 4.8 & 1.5 & 2.3 & 4 \\
\hline- & - & - & 9.0 & 9.0 & 8.7 & 5.5 & 5.1 & 2.5 & 2.2 & 5 \\
\hline- & - & - & 9.0 & 7.2 & 8.5 & 7.5 & 7.5 & 1.7 & 2.7 & 6 \\
\hline
\end{tabular}

* وسط اكار الكلوتين

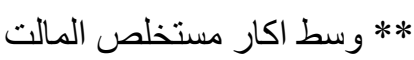

الكربوهيدرات أو انعدامها كلياً ولكنه يحوي على

العناصر الضرورية للنمو [4 ، 5] .

أظهرت نتائج تتمية الفطر على وسط الكلوتين

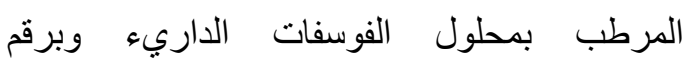
هيدروجيني (5) ونسبة ترطيب (2 : 1) حجم : وزن واستخلاص الانزيم كفاءة الفطر في انتاج البروتيز الحامضي على هذا الوسط . جدول (2) يوضح الفعالية الانزيمية والنوعية والانتاجية للبروتييز

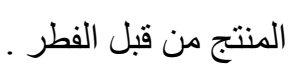

جدول (2) الفعالية الانزيمية والنوعية والانتاجية للبروتييز المنتج على وسط اكار الكلوتين المرطب

\begin{tabular}{|c|c|c|}
\hline الفعالية النوعية (وحدة/ملفم) & الانتاجية (وحدة/غم) & فعالية الانزيم (وحدة/مل) \\
\hline 258.69 & 908.46 & 151.41 \\
\hline
\end{tabular}


الرقم الهيدروجيني (7) حيث بلغت (713.65)

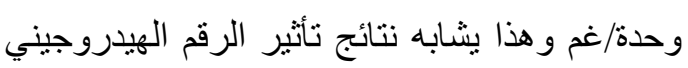

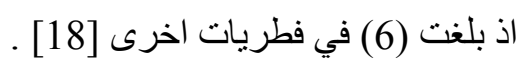

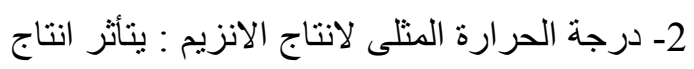
الانزيم بمدى تغير درجة الحرارة فقد أظهرت نتائج تنمية الفطر بدرجات حرارية مختلفة تراوحت بين (25-25) م شكل (25) عدم اختلاف الانتاجية بزيادة درجات الحرارة وبلغت بدرجة 35 م قيمة (1143.84) وحدة/غم كلوتين . لقد توافقت درجة الحرارة المتلى لانتاج الانزيم هذه مع نتائج در اسات

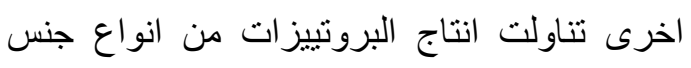
Aspergillus

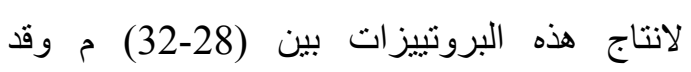
أوضحت هذه الدراسات ان أي تغير في درجات

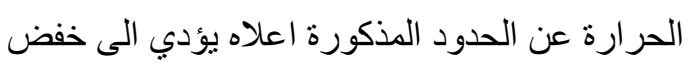
فعالية الانزيم [24 ، 25] ـ 3- محلول الترطيب الأمثل لانتاج الانزيم : أظهرت نتائج ترطيب الكلوتين بمحاليل ترطيب مختلفة وبنسبة (2 : 1)حجم:وزن شكل (C-2) بأن لمحلول

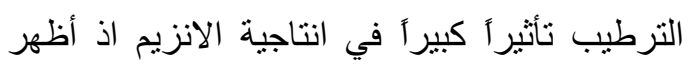

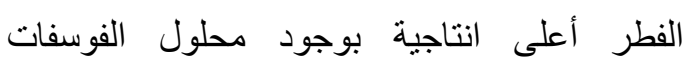
الداريء وبقيمة (950.19) وحدة/غم و أقل انتاجية

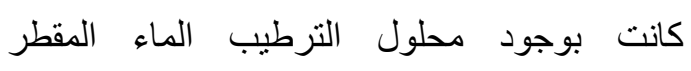
(846.53) وحدة/غم . مما يدل على أهمية املاح

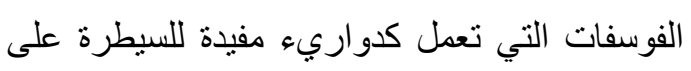
تغيرات الرقم الهيدروجيني أي لها القابلية في

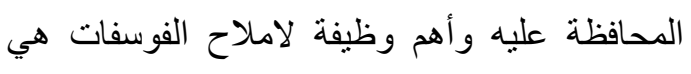

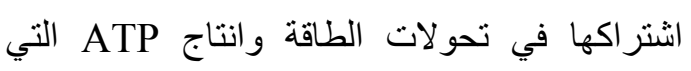
تستعمل في تخليق البروتينات . 4- محلول الاستخلاص الامثل : أظهرت نتائج استخلاص الانزيم بمحاليل استخلاص مختلفة وبقيم هيدروجينية (5-5.5) شكل (2-D) تباينا في الفعالية
ـ تعيين الرقم الهيدروجيني الامثل لفعالية وثبات الانزيم أظهرت نتائج تنمية الفطر في وسط كلوتين الذرة بقيم هيدروجينية مختلفة نراوحت بين (2-7) وقياس فعالية انزيم البروتييز الخام شكل (A-1-1) ان المدى لهى الامنل لفعالية الانزيم كانت بين (4-6) و اعلى فعالية للانزيم في الدالة الحامضية (6) وبلغت (135.58) وحدة /مل وبانتاجية تعادل (813.46) وحدة/غم أما

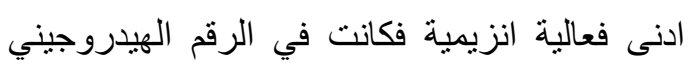
(7) وبقيمة (107.63) وحدة/مل و وانتاجية (645.78) وحدة/غم كلوتين ـ لذلك يمكن اعتبار الانزيم المستخلص من البروتييزات الحامضية بغياب المواصفات الاخرى [19 ، 20] ـ أما ثبات الانزيم بالقيم الهيدروجينية المختلفة فنشهدت الفعالية استقرارَ نسبياً في القيم الهيدروجينية (2-5) ثمينم ازدادت في القيمة الهيدروجينية (7) كذلك الحال في

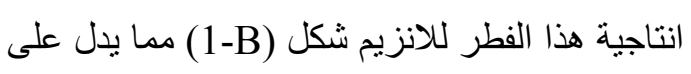

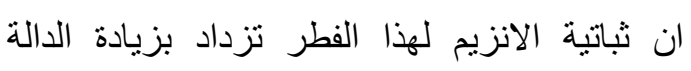
الحامضية حتى بلغ اعلاها في الدالة (7) ، وقد لاحظ ترن

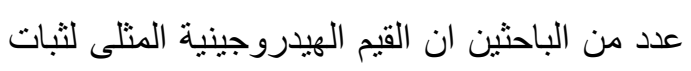

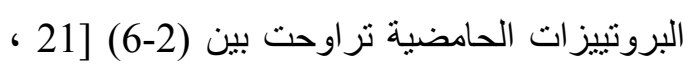

ـ تعيين الظروف المنلى لانتاج البروتييز الحامضي

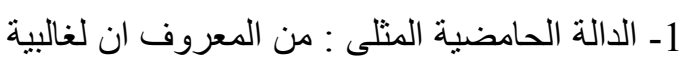
الفطريات القابلية على النمو في مدى واسع من الرقم الهيدروجيني (2-8) ولكنها تفضل الوسط الحامضي

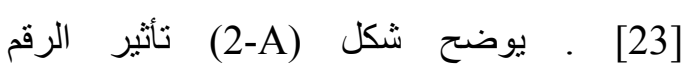
الهيدروجيني في انتاجية الفطر لانزيم البروتييز اذ

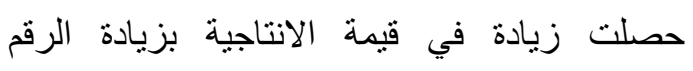

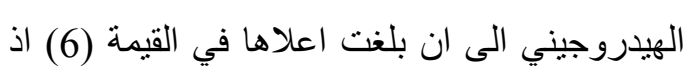
بلغت (1128.46) وحدة/غم كلوتين ومن ثم حدث انخفاض حاد بلغ (50\%) من قيمة الانتاجية في 
بلغت (817.30) وحدة/غم شكل (2-E) . ماما

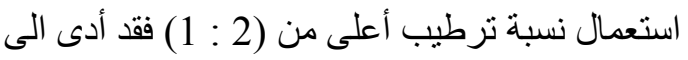
بقاء قسم من المحلول دون امتصاص مما يؤدي الى ظهور الطور السائل في المحلول لذلك استبعدت نسبة الترطيب الاعلى من (2 : 1) نظرا لقابلية

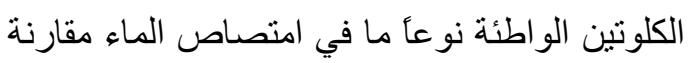
باوساط التخمر الاخرى مثل النخالة . ان حدود الترطيب يجب ان تكون متلائمة مع قابلية الامتصاص فبقاء الماء أو المحلول المرطب بين المسافات البينية سيزيح الهو اء فيما يؤثر سلباً في نمو لاهو الفطر و انتاج الانزيمات الخارجية [29] . وقد تباينت نسبة الترطيب المثلى لانتاج انزيمات

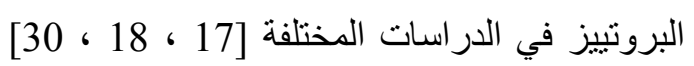

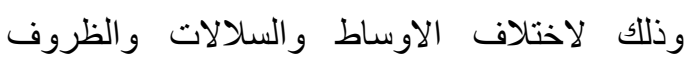
المستخدمة . 6- حجم اللقاح الامثل لانتاج الانزيم : أظهرت النتائج شكل (2-F) تباينأ في الانتاجية اذ اظهرت أعلى انتاجية عند استعمال مستوى لقاح (10) (10) بوغ/غم وزن الكلوتين وبقيمة (1050.57) وحدة/غم كلوتين ـ تتفق هذه النتائج مع العديد من الباحثين في وني

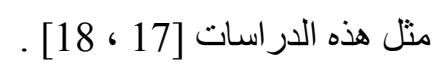
7- مدة الحضانة المنلى لانتاج الانزيم : يوضح الثكل (2-G) تأثير مدة الحضانة في انتاج الانزيم حيث أظهر أعلى انتاجية في اليوم الرابع من لندانير الحضانة بقيمة (933.07) وحدة/غم كلوتين و انخفضت بعد ذلك تدريجياً ابتداءَ من اليوم الخامس وهاع

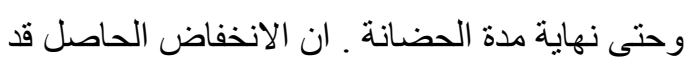
يعود الى تأثير الانزيمات نفسها بفعل الهضم

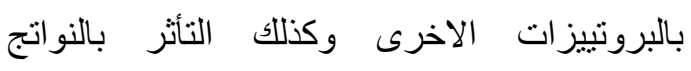
العرضية التي تكثر في البيئات الموضعية التي تنشأ حول الخلايا و التي تتفاقم مشكلتها في حالة تخمرات المو اد الصلبة باعتبار ها أنظمة مفيدة نو عاً ما [17 ،
النوعية للانزيم باختلاف محاليل الاستخلاص ، اذ أظهر الانزيم المستخلص أعلى فعالية نوعية بمحلول

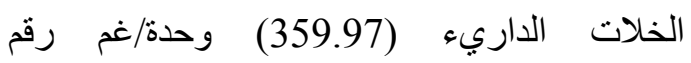
هيدروجيني (5) ، و انخفضت الفعالية نسبياً في محاليل الاستخلاص الفوسفات و والماء المقطر و السترات ـ و هذا ما يتو افق مع نتائج اخرى [17]

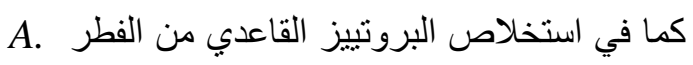

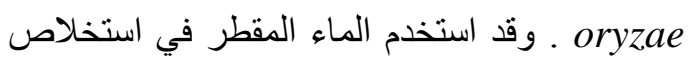

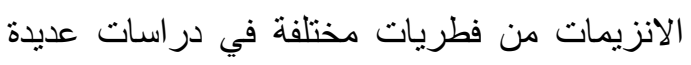
[25، 26] ـ كما استخدم محلول الفوسفات الداريء كذلك من قبل عدد من الباحثين [18 186 ، 27 ـ ـ ويعود

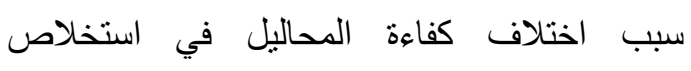
الانزيمات من تخمرات المواد الصلبة الى اختلاف

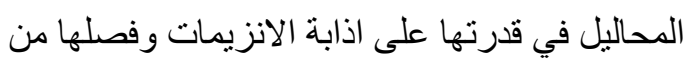
مكونات الوسط غير الذائبة بسبب القوة الايونية

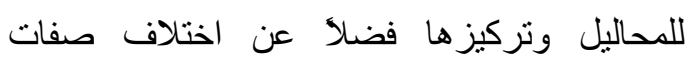
الانزيمات ذاتها كنقاط تعادلها الكهربائي وثباتها تجاه القيم الهيدروجينية و غير ها ـ الهير 5- نسبة الترطيب المتلى لانتاج البروتييز : ان اندئل

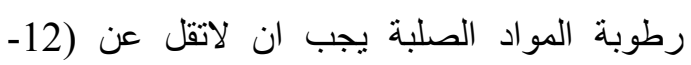
15\%) باعتبار ها الحد الادنى الذي يؤدي الى توقف لهون

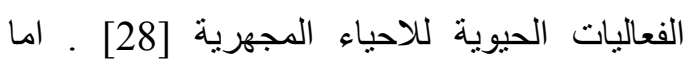

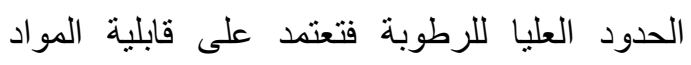
الاولية في امتصاص الماء والمحاليل المرطبة التي لئي تعتمد بدور ها على حجم دقائق المواد الاولية ودرجة مساميتها ولذلك كانت نسبة الترطيب (2:1) حجم:وزن ملائمة جداً حيث أظهرت نتائج ترطيب

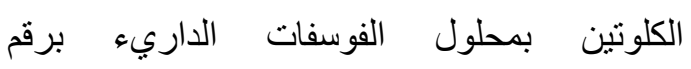
هيدروجيني (5) تقارب في الانتاجية باختلاف نسبة

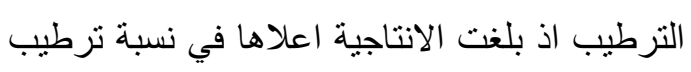
(2 : 1 1 ) وهي (908.30) وحدة/غم ، وفي نسبة ترطيب (1 : 1) قلت الانتاجية بشكل طفيف حيث 
يوصى باستغلالها لعمل أوساط زرعية لتتمية الفطريات فضلا عن امكانية استخدامها كأوساط تخمرات صلبة لانتاج البروتييزات ـ كما ان الفطر

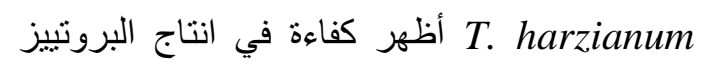
الحامضي والذي يحتمل ان يعود الى مجموعة

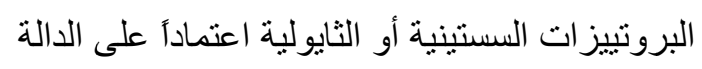

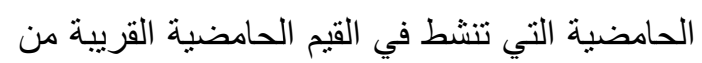

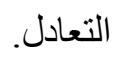

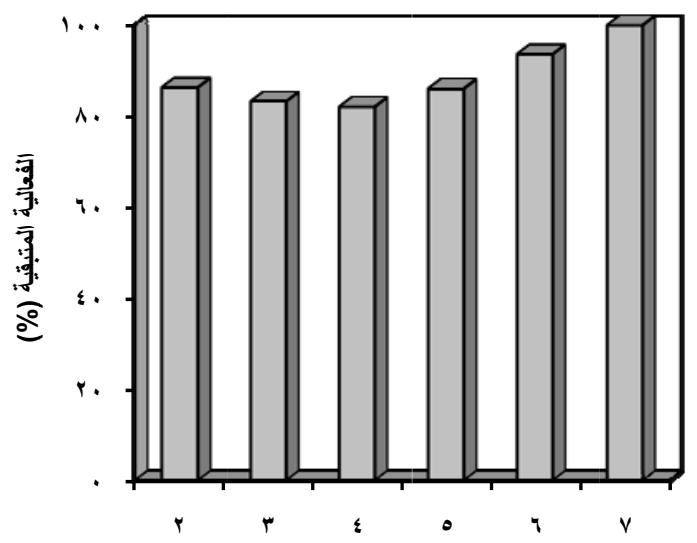

) ، وثبات الانزيم(B) بدرجة حرارة (30)م
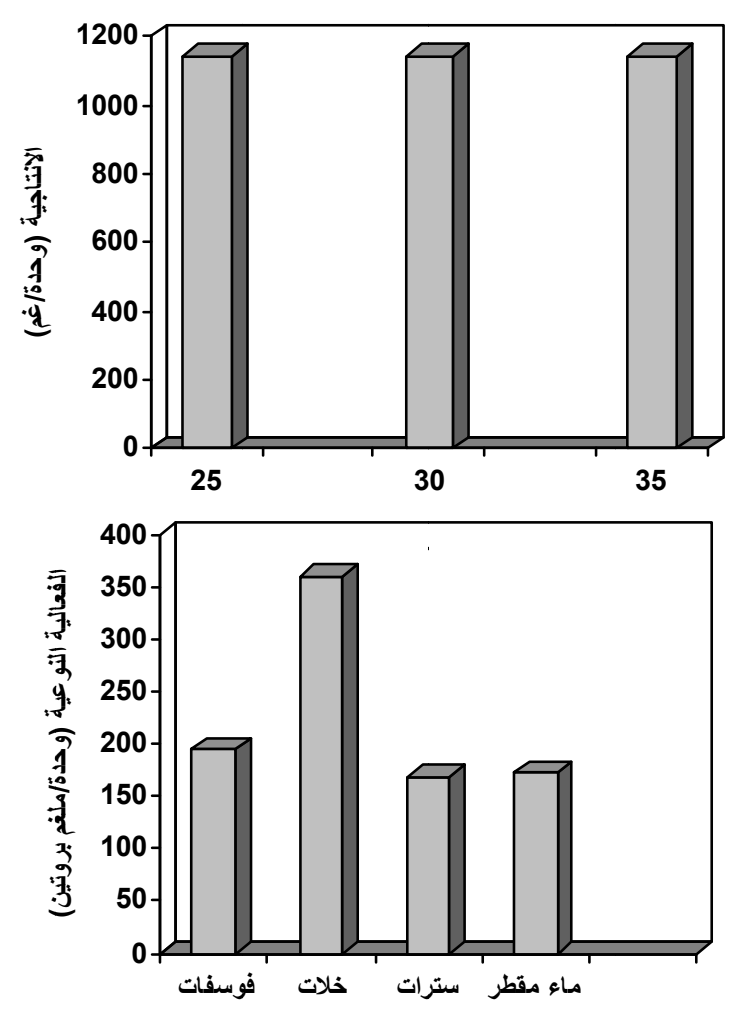

28] ـ تتفق هذه الدراسة مع عدد من الدراسات التي

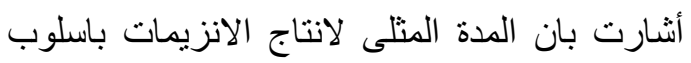
تخمر ات المواد الصلبة نراوحت بين (2-7) أيام [31 بنان

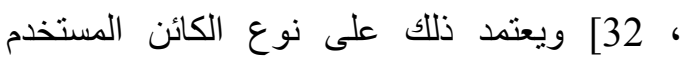
و الوسط وظروف التنمية .

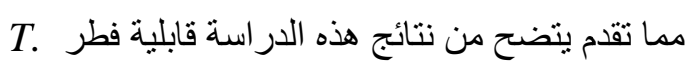

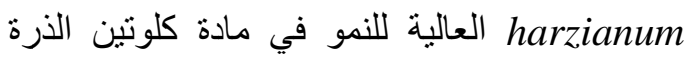
(الجزء غير الذائب) وهي احدى المخلفات النباتية

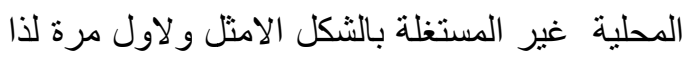

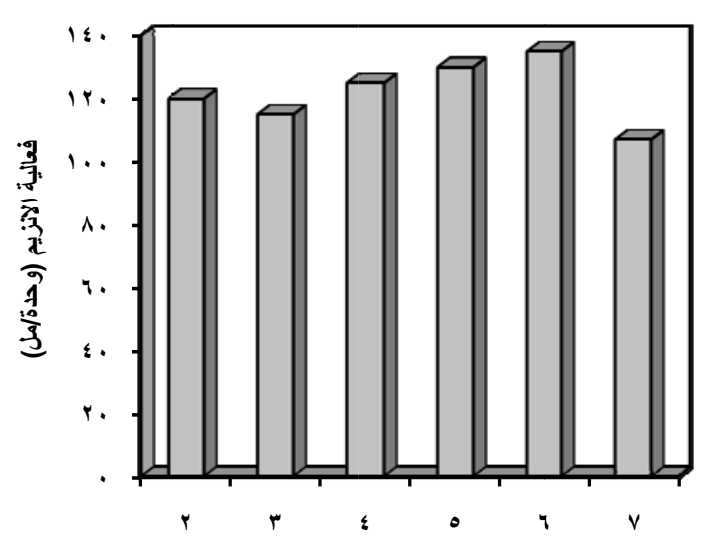

شكل (1) تأثير الرقم الهيدروجيني في فعالية (A)، وف
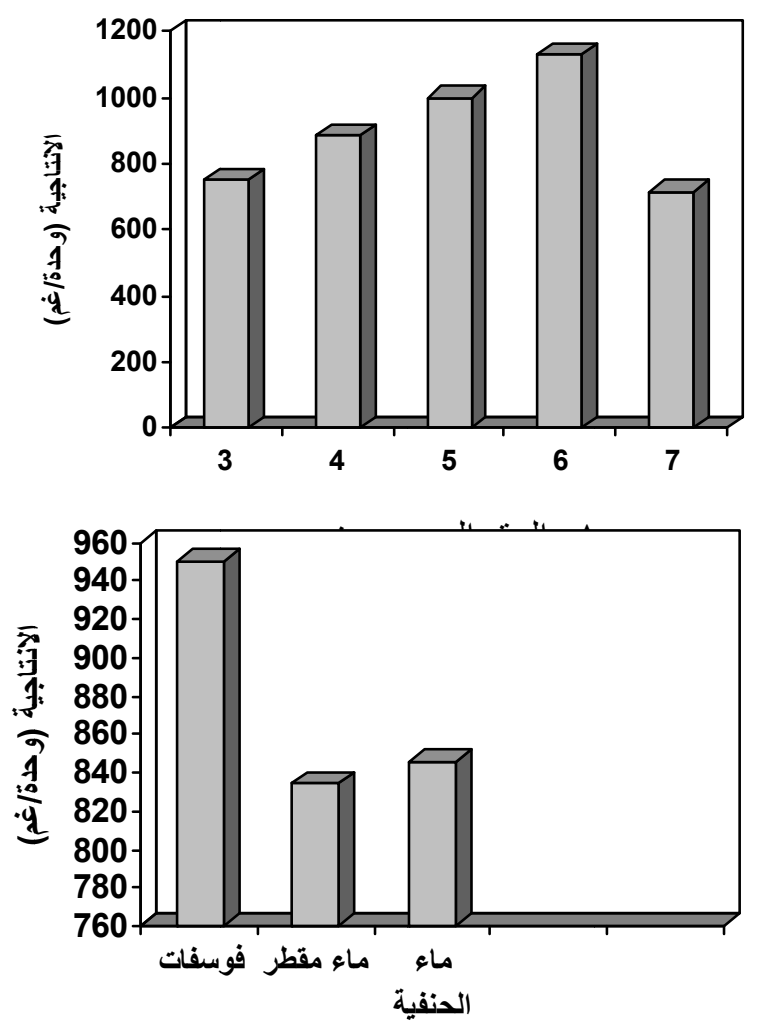


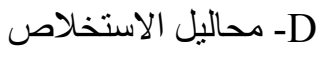

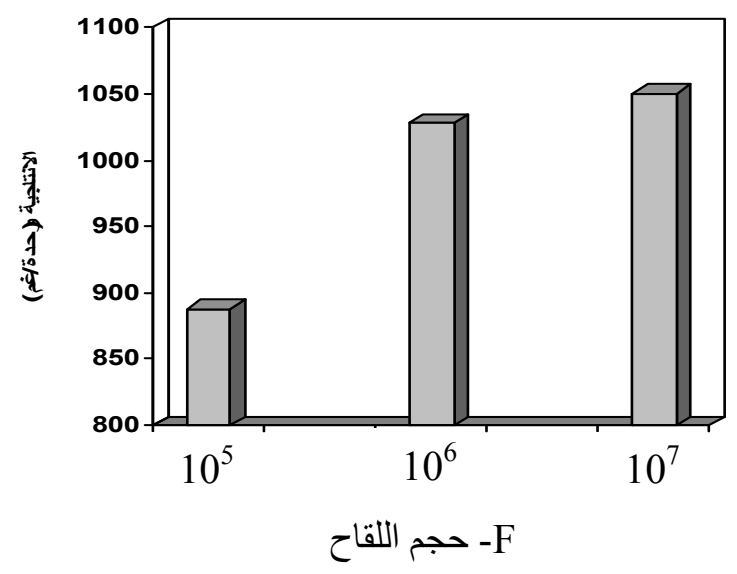

- محاليل الترطيب - C

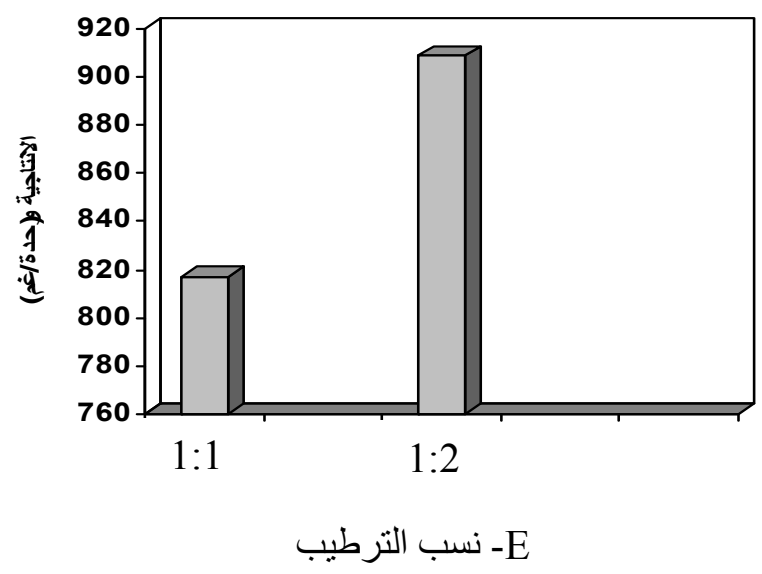

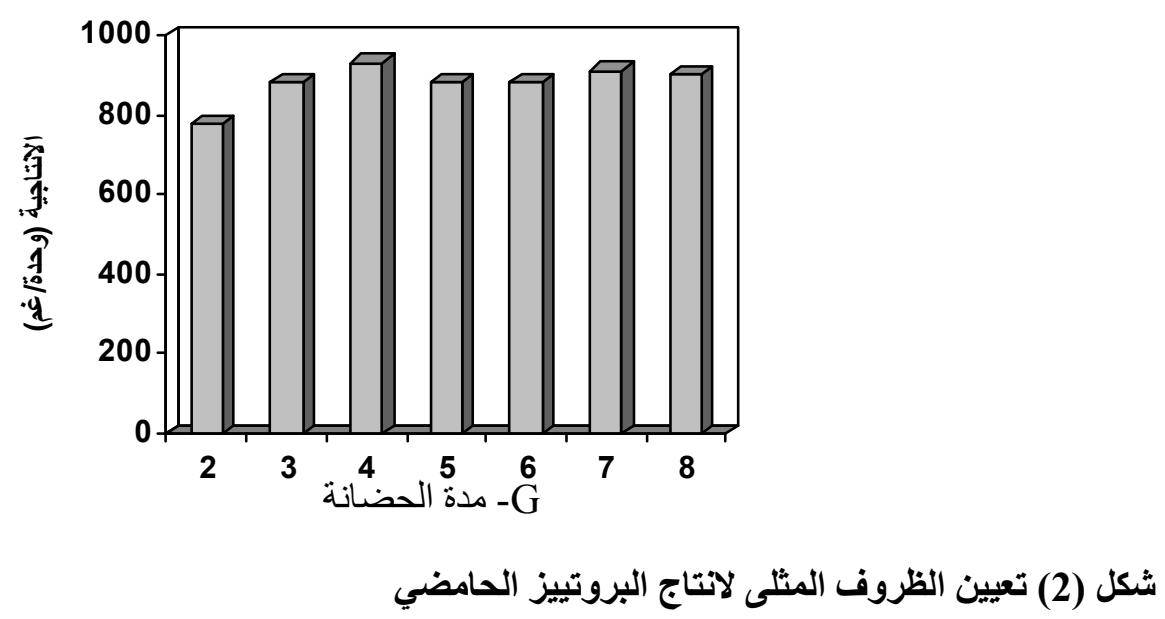

المصادر

Blakerough, (Eds.) . Hartwood Arnold. 1. Trevan, M.D.; Boffey, S.; Goulding, England.

K.H. and Stanbury, P. (1995).

3. Böing, J.T.P. (1982). Enzyme Biotechnology: The biological production. In: "Prescott and Dunn's Industrial Microbiology. G. Reed, (Ed.) principles. McGraw Hill Pub.Co.Ltd, New Delhi.

. AVI Publ. Company Inc. West Port, C.T. USA. PP 634-708.

2. Dunill, P. (1980). The current status of 4. الخفاجي، زهرة محمود؛ القاضي، مها طارق؛ عبد enzymes technology, In: "Enzymatic الحميد ، ريم فالح والحكالك ، ثريا صنادق and Nonenzymatic Catalysis" P. (2002a). تحضير اوساط زرعية لتنمية وعزل Dunill,; A. Wiseman, and N. 
11. Murachi, T. (1970). Bromelain enzymes. In: "Methods in Enzymology". Perlman, G. and Lorand, L. (Eds.). Academic Press. New York. Vol.19: 273-284.

12. Whitaker, J.R. and Granum, P.E. (1980). An absolute method for protein determination based on difference in absorbance at 235 and $280 \mathrm{~nm}$. J. Anal. Biochem, 109 : 156-159 .

13. Aidoo, K.E.; Hendry, R. and Wood, J.B. (1982). Solid state fermentation. In: Advance Appl. Microbiol., 28 : 201-237 .

14. Mudgett, R.E.; Nash, J. and Rufiner, R. (1982). Controlled Gas Environments in solid substrate fermentations. In: "Developments in industrial microbiology". Proceeding. of the $38^{\text {th }}$ General Meeting of Society for Industrial Microbiology. Arlington, Virginia. Pp. 393-405.

15. Bergkvist, R. (1963). The proteolytic enzymes of Aspergillus oryzae. Methods for the estimation and isolation of the proteolytic enzymes . Acta . Chem. Scand. 17 : 1521-1540 .

16. Al-Taii, W.F.; Tagi, N.K.; AlNakkashe, Sh.M. and Al-Ogaidi, H.A. (1988). Screening of fungal strains for protease production. J. Agric. Water Res., $7: 11-24$.
بكتريا حلمض اللاكتيك ـ المؤتمر العلمي الثامن للتعليم التقني .

5. الخفاجي، زهرة محمود ; ابراهيم، ثريا خليل;

القاضي، مها طارق وعبدالحميد ، ريم فالح (2002b) ( استعمال مخلفات صناعة نشأ الذرة

لتنمية الفطريات ـ المؤتمر العلمي الثامن للتعليم

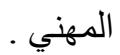
6. محمد، لينا جاسم (2002) ـ امكانية استغلال كلوتين الذرة كوسط ملائم لتنمية الفطريات وانتاج انزيم البروتييز الحامضي . رسالة ماجستير . جامعة بغداد ، كلية التربية ابن الهيثم .

7. BBL Manual of Products and Laboratory Producers. (1973). Division of Becton. Dickinson Co. Maryland .

8. Ustyuzhanina, S.V.; Yaroveukom, V.L. and Voinarskii, I.N. (1985). Synthesis of protease and alpha-amylase by washed cells of the fungus Aspergillus oryzae. Appl. Biochem. Microbiol. 22: $55-58$.

9. Bhumiratana, A.; Flegel, T.W.; Glinsukon, T. and Somporan, W. (1980). Isolation and analysis of mold from soy sauce koji in Thailand. Appl. Environ. Microbiol., 39 : 430-435 .

10. Bottaro-Castilla, H.R.; Waechaer, R.S.; Meinardi, C.A.; Zalazar, C.A. and Fraile, E.R. (1982) . Production of acid proteinase concentrate from Mucor bacilliformis. Revista Argentina de Microbioo., 14(2): 115-118[DSA (1984) 46(12)958] . 
24. Sharma, O.P. and Sharma, K.D. (1980). Studies on in vitro production of proteolytic enzymes leather deteriorating fungi Revue Romaine De Biochimie., 17 : 209-215 .

25. Malathi, S. and Chakroborty, R. (1991). Production of alkaline protease by a new Aspergillus flavus isolates under solid state fermentation conductions for uses of depilation agents. Appl. Environ.Microbiol., 55 : 712-716.

26. Berovic, M. and Logan-Derencin, M. (1993). Solid state fermentation of pectinolytic enzymes by Aspergillus niger. J. Chem. Tech. Biotecnolog., 58 : 209-211 .

27. Impoolsup, A.; Bhumiratana, A. and Flegel, T.W. (1981). Isolation of alkaline and neutral proteases from Aspergillus flavus var. Columnaris, a soy sauce koji mold. Appl.Environ.Microbiol., 42 : 619-628

28. Smith, J. (1985). Principles of Biotechnology. Cambridge University Press. London .

29. Narahara, H.; Koyama, Y. and Yoshida, T. (1984) . Control of water content in solid state culture of Aspergillus oryzae .J.Ferm.Technol., $62: 435-439$.

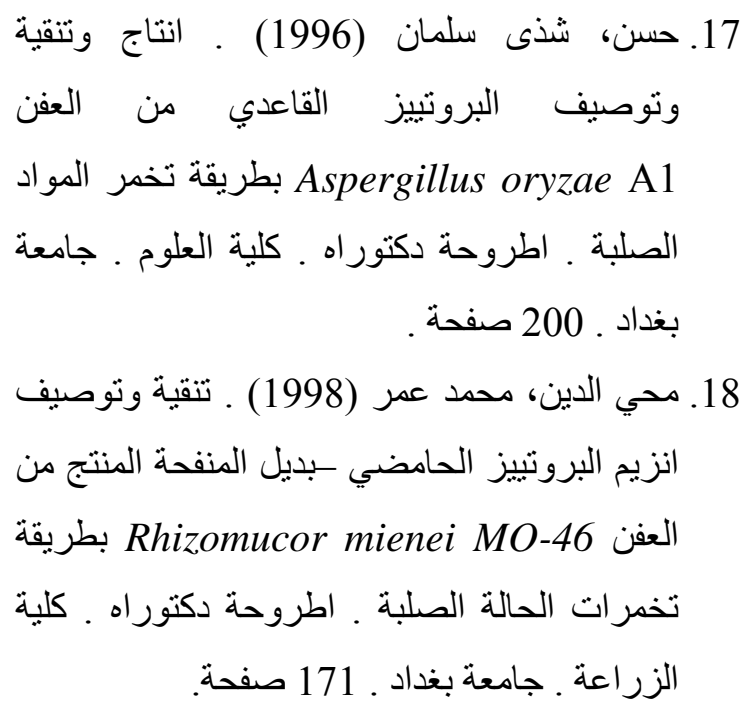

19. Aunstrup, K. n (1980) . Proteinases. In : Microbial Enzymes and Bioconversions . Rose, A.H. (Ed.). Academic Press . New York, pp 49114 .

20. North, M.J. (1982). Comparative biochemistry of the proteinases of eukaryotic microorganisms. Microbiol. Rev., $46: 308-340$.

21. Matsubara, H. and Feder, J. (1971) . Other Bacterial, Mold and Yeast Proteases . In: "The Enzymes. Boyers, P.D. (Ed.). Academic Press Inc . New York. Vol. 3:721-730 .

22. Borriss, R. (1987). Biology of Enzymes. In: Biotechnology. Rhem, J.H. and Reed, G. (Eds.). VCH Deer field Beach. Vo. 7a: 35-56.

23. Freizer, W.C. (1967). Food Microbiology Mcgrow Hill Book Co., New York . 
Cultre requirements fpr the production of protease by Aspergillus oryzae in solid state fermentation . Appl. Microbiol.Biotechnol., 35: 292-296. 32- سعيد ، اكرم ثابت محمد (1996) . ـ انتاج الاميليزات من الفطر group الحالة الصلبة ـ اطروحة دكتوراه ـ كلية الزراعة .

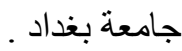

30. Bottaro-Castilla, H.R.; Waechaer, R.S.; Meinnard, C.A.; Zalazar, C.A. and Fraile, E.R. (1982). Production of acid proteinase concentrates from Mucor bacilliformis. Revista Argntina de Microbio., 14 : 115-118 [DSA (1984) 46(12)958].

31. Battaglino, R.A.; Huergo, M.; Pilosof, M.R. and Bartholomai, G.B. (1991) . 